\title{
The Development of Isolated Blastomeres in Bithynia tentaculata (Prosobranchia, Gastropoda)
}

\author{
N. H. VERDONK 1 AND JAMES N. CATHER 2 \\ Zoological Laboratory, University of Utrecht and The Department of \\ Zoology, University of Michigan, Ann Arbor, Michigan 48104
}

\begin{abstract}
The development of isolated blastomeres, separated at the first and second cleavage has been studied. After separation at the first cleavage, one half-embryo (CD) becomes swollen and balloon-like and develops adult organs such as eyes, tentacles, shell, operculum, etc. The other half (AB) is much more compact and never develops these adult structures.

After separation on the alternate axis at the second cleavage to produce $\mathrm{AD}$ and $\mathrm{BC}$ halves, both halves could form all adult structures.

These results indicate an equivalent organizing capacity of the $C$ and $D$ quadrants contrary to most spiralians, such as Ilyanassa, where the D quadrant alone exerts the major organizational influence.

The experimental evidence is discussed in relation to the distribution of the cytoplasmic vegetal body, rich in RNA, which is passed to the $\mathrm{CD}$ blastomere in the polar lobe and then evidently equally distributed to $\mathrm{C}$ and $\mathrm{D}$.
\end{abstract}

Crampton (1896) first studied the development of isolated blastomeres in gastropods, using Ilyanassa, Urosalpinx and Anachis. He found that the separated cells underwent cleavage in a pattern typical of the part of the normal embryo from which they originated and not at all comparable to that of the whole embryo. A more extensive study on the developmental potencies of isolated blastomeres was carried out by Wilson ( $04 a, b)$ with eggs of the gastropod Patella and the scaphopod Dentalium. Wilson succeeded in rearing the isolated cells to a stage where larval structures appeared. He concluded that isolated cells can give rise to the same structures as they would have done as a part of the whole embryo. In addition, he established the important role of the polar lobe in the development of Dentalium, for after removal of this lobe at first cleavage a defective larva was formed without apical tuft and posttrochal region. Similar results were obtained by Rattenbury and Berg ('54) studying the development of lobeless embryos and isolated blastomeres of the bivalve Mytilus. Studies of isolated blastomeres in other spiralians have recently been reviewed by Cather (71). The most penetrating studies on the significance of the polar lobe for development and on the potencies of indi- vidual blastomeres are those of Clement (52, '56, '62) carried out with eggs of the mudsnail Ilyanassa. Clement showed that after removal of the polar lobe at the trefoil stage all distinctive features of the cleavage in the $\mathrm{D}$ quadrant are lost, so that cleavage becomes identical in all quadrants. In the lobeless larva no adult structures such as foot, eyes, tentacles, etc., originate. Clement's study of isolated blastomeres showed that adult structures only develop from the D macromere or combinations including it. The A, B, or C blastomeres always develop like lobeless embryos. Extending this study Clement removed the $\mathrm{D}$ macromere at successive stages. It appeared that removal of $\mathrm{D}, 1 \mathrm{D}$ and $2 \mathrm{D}$ has approximately the same consequences for later development as removal of the polar lobe, but after removal of 3D a larva with eyes, velum, shell and foot may develop. When only 4D is deleted even the heart and intestine are added to form a small but perfect larva.

Hess ('56) succeeded in separating the blastomeres of the fresh-water prosobranch Bithynia tentaculata. He studied the cleav-

\footnotetext{
1 Present address: Zoological Laboratory, Janskerkhof 3, Utrecht, The Netherlands.

2 Supported in part by institutional research grant IN-40M to the University of Michigan from the American Cancer Society.
} 
age and the early development of isolated blastomeres. However, he failed to rear a sufficient number of 1/2- and 2/4-embryos to a stage, at which organogenesis occurred, so that little is known about the potencies of the blastomeres. Since $B i$ thynia has a very small polar lobe (20$30 \mu$ ) which is very difficult to remove, a comparison of the development of isolated blastomeres which receive or do not receive polar" lobe material can determine, whether such a small lobe has a comparable influence on development to the much larger lobe of Ilyanassa.

\section{MATERIAL AND METHODS}

Eggs used in these experiments were obtained from snails (Bithynia tentaculata) taken from ditches near Utrecht. The snails were kept in glass aquaria in the laboratory where spontaneously laid egg masses were collected from leaves of waterplants at regular intervals. The separation of blastomeres was carried out in small wax-bottom dishes. A small opening was made in the capsule wall with a sharp knife. A pointed hair, inserted through this opening, was used to separate the blastomeres in the capsule. As already observed by Hess ('56) the opening in the capsule is soon closed, apparently by a coagulation of the capsule fluid. In control experiments such an opening did not appear to be harmful to the developing embryo. About $50 \%$ of the eggs in an egg mass were operated, the remaining eggs served as controls.

After the operations an egg mass was transferred to a small covered dish (Boveri type) of copper-free tapwater. The eggs were cultured at $25^{\circ} \mathrm{C}$ and inspected daily. After inspection an egg mass was cleaned on moistened filter paper and transferred to a clean dish. When one of the half embryos of a pair, originating from the same egg, died, the other was discarded.

Control embryos, reared at $25^{\circ} \mathrm{C}$, leave their capsules after 12-14 days. As the development of the half embryos sometimes seemed to be retarded, we tried to keep them alive as long as possible. However, nearly all half embryos died after about 17 or 18 days. Therefore the half embryos were cultured for 14-16 days. When both partners of a pair originating from a single egg, were still alive, they were either stained directly with silver nitrate (Verdonk, '65), or fixed in Bouin's fluid. The silver-stained embryos were dehydrated and mounted in balsam with the cover glass supported by a thick piece of paper. In this way the whole embryo can be oriented as desired and studied in detail. The embryos fixed in Bouin's fluid were treated according to usual histological methods. Serial sections of $5 \mu$ were stained with iron haematoxylin and eosin.

To enable comparison of organs and anlagen of organs found in half embryos with those of normal embryos, a series of normal embryos ranging from 5 to 16 days were similarly prepared.

\section{RESULTS}

\section{A. The development of $A B$ - and CD-halves}

The separation of blastomeres was carried out after the completion of first cleavage, when the blastomeres started flattening against each other. A total of 574 eggs from 130 egg masses were operated on; in only 80 cases did both halves stay alive long enough for the development of adult organs $\left(14-16\right.$ days at $\left.25^{\circ} \mathrm{C}\right)$.

During the first days of development both halves swell but not to the same extent. One half forms a balloon-like embryo, which has at one side a compact mass, from which most of the adult organs originate. The other half develops into a more compact structure, lacking most organs. Fifty-five pairs of half embryos were studied as whole mounts after staining with silver nitrate. The results are shown in table 1. Large ectodermal cells, partly covered with cilia are always present in both halves. They represent the larval head cells which form such structures as the head vesicle, apical plate and velum, although they are never organized as in a normal head. Adult organs were always observed in the balloon-like half. So in 30 cases an eye (even two eyes in seven cases) was present in this half. In three cases a pigment spot (in one case four such spots) was observed in the compact half, which lacked the other adult organs. These spots could possibly represent eyes, but this seems doubtful as they were never observed in the sectioned embryos (see below). 
TABLE 1

Summary of structures present in 55 pairs of half-embryos ( $A B$ and $C D$ ) studied as whole mounts after silver staining

\begin{tabular}{lccc}
\hline Organs & $\begin{array}{c}\text { Present in } \\
\text { both halves }\end{array}$ & $\begin{array}{c}\text { Present in } \\
\text { one half only }\end{array}$ & $\begin{array}{c}\text { Absent in } \\
\text { both halves }\end{array}$ \\
\hline Larval head structures & 55 & - & - \\
Eye & $3 ?$ & 30 & 22 \\
Tentacle & $3 ?$ & $22 ?$ & 30 \\
Shell & - & 34 & 21 \\
Operculum & - & 14 & 41 \\
Gills & - & 2 & 53 \\
\hline
\end{tabular}

Whereas an eye was present in the swollen half, a tentacle-like structure was found in most cases in the compact half. In only three cases were they observed in both halves.

Shell (34 cases) and operculum (14 cases) were always limited to the swollen half. Gills were observed only twice, also in the swollen half. An example of two half-embryos, originating from the same egg is shown in figure 1.

The results of the study of sections of 25 pairs of half-embryos are shown in table 2. As in the whole mounts significant differences were apparent between the two partners of a pair, originating from the same egg. One half always showed a compact structure and was filled with muscle cells and mesenchyme cells (plate 1 ; fig. 3). The other half-embryo showed well developed organs often grouped together, with the rest of the embryo swollen into the previously described balloonlike vesicle (plate 1; fig. 4). Larval head cells were always present in both halves but they never formed a complete head vesicle or velum. A well-developed eye was always restricted to one half. In 16 cases the eye was single; in three cases two eyes were present in the same half. In two cases one partner had a well-developed eye, while the other showed a small unpigmented vesicle, which possibly could represent the early anlage of an eye.
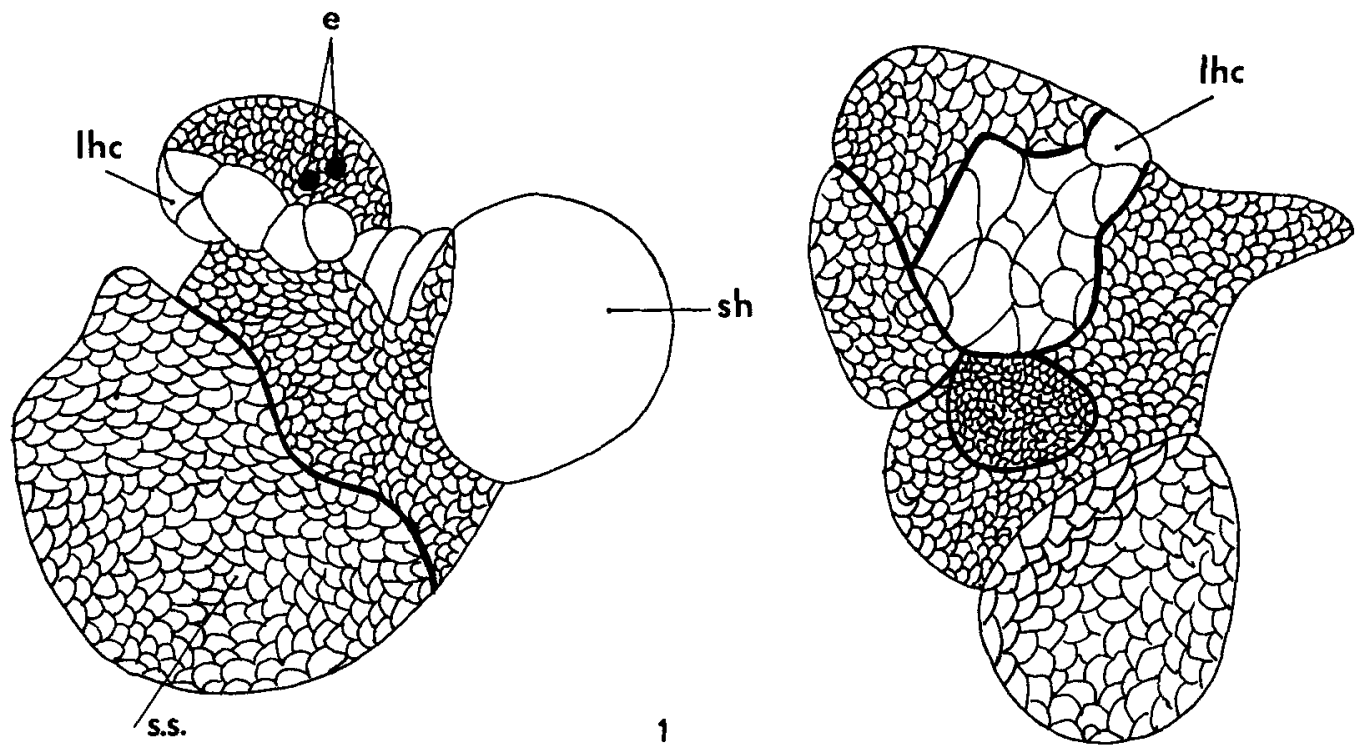

Fig. 1 Silverstained whole mounts of two 1/2-embryos from a single egg. The left one shows two eyes (e), shell (sh) and a row of larval head cells (lhc). All these structures are situated at one side, whereas the other side consists of a swollen sac (ss), which partially collapsed in the silver nitrate. In the other half-embryo (to the right) only larval head cells are recognizable. No adult structures present. 
TABLE 2

Summary of structures present in 25 pairs of half-embryos ( $A B$ and $C D$ ) studied in sections

\begin{tabular}{|c|c|c|c|}
\hline Organs & $\begin{array}{l}\text { Present in } \\
\text { both halves }\end{array}$ & $\begin{array}{l}\text { Present in } \\
\text { one half only }\end{array}$ & $\begin{array}{c}\text { Absent in } \\
\text { both halves }\end{array}$ \\
\hline Larval head structures & 25 & - & - \\
\hline Eye & $2 ?$ & 19 & 4 \\
\hline Tentacle & - & 2 & 23 \\
\hline Shell & - & 23 & 2 \\
\hline Operculum & - & 21 & 4 \\
\hline Gills & - & 2 & 23 \\
\hline Foot & - & 5 & 20 \\
\hline Statocyst & - & 24 & 1 \\
\hline Ganglia & 25 & - & - \\
\hline Muscles & 25 & - & - \\
\hline Foregut & - & 12 & 13 \\
\hline Midgut & 25 & - & - \\
\hline Hindgut & 3 & 14 & 8 \\
\hline
\end{tabular}

Apparent pigment spots, observed in living compact halves, were never seen in sections nor were any other specific eye structures present.

Tentacle-like structures, mostly filled with muscle cells were often observed in the compact half-embryos, but after closer examination it seems doubtful whether they are true tentacles. Short bristles, typical of tentacles in normal embryos, were never observed. Similar structures, filled with muscle cells, but not showing the shape of a tentacle are often present. An eye was never observed at the base of these structures. For these reasons we do not consider them as tentacles and most of the tentacle-like structures, observed in whole mounts, most probably belong to the same category.

With one exception at least one statocyst was present in one half of a pair; in eight cases two and in three cases three statocysts were found in the same half.

Ganglia were always observed in both halves. As these ganglia in all half-embryos are apparently situated more or less randomly, it was impossible to identify them specifically.

Shell, recognizable by its shape and structure, was in all cases (23) restricted to one half; in two cases two shell plates and in one case three shell plates were present in the same half embryo. Most of the embryos with a shell also had one or two opercula; only two half-embryos had a shell but no operculum.

A rather well-shaped foot was observed in five half-embryos. All swollen half-embryos showed areas, which histologically resemble the foot, consisting of typical columnar cells with short cilia, often interspersed with mucous cells. The operculum was situated either in this area or very close to it. Gills were observed only twice.

In 13 living half-embryos a beating larval heart was observed, which was always restricted to one half. This thinwalled vesicle, described by von Erlanger (1892), could not be identified in most of the sectioned embryos. In sections of five half-embryos a cavity was found, lined by flat cells, which resembled the cells of the pericardial cavity in normal embryos of eight days. An adult-type heart or kidney was never observed.

As mentioned above muscle cells are abundant in the compact halves; in the swollen halves muscle cells are rather scarce, but usually better developed.

In normal embryos the entrance of the stomodaeum is characterized by elongated cells with clear cytoplasm. Small granules are present near the surface where long cilia protrude. These cells are very distinct at the veliger stage (seven to eight days) but in normal embryos of 16 days, which have a well developed mouth cavity, they are no longer distinguishable. Although the half-embryos were maintained for a period of 14-16 days stomodaeum entrance cells were still observed in some cases, but always restricted to the swollen half of a pair. In other swollen embryos a buccal cavity was observed and in one case there was even a well developed radula. Stomach tissue was limited also to the swollen partner. As in Ilyanassa 
(Atkinson, '71) the stomach is characterized by an extra-cellular layer stained grayish with iron haematoxylin and sometimes accompanied by a part of a style sac with characteristic stiff cilia. The part of the midgut, which was always present in both halves was the larval liver, sometimes covering a part of the surface but usually forming a mass with or without a lumen inside the embryo.

Hindgut was observed three times in both halves of a pair; 14 times in one half only and in eight pairs of embryos it was not observed. In 12 half-embryos the hindgut connected the midgut with the exterior; in four cases it arose from the midgut but the other end was closed, while in four other cases there was no connection with the midgut.

In order to determine which half represents the AB-half, blastomeres were separated immediately after first cleavage, when the polar lobe was still rounded off with respect to the blastomeres. In most cases the eggs cytolized, most probably because the blastomeres still retained cytoplasmic connections with each other. In a few cases, however, both blastomeres stayed alive and the half with the polar lobe could be distinguished. Sometimes the lobe did not fuse. The reason may be that it remained in contact with the ABblastomere and was unable to fuse (cf. Verdonk, '68). After the polar lobe fused with one of the blastomeres this blastomere was killed. Six half-embryos, known to have originated from the AB-blastomere, were reared for 15 days. After studying sections of these embryos it was apparent that adult organs such as eyes, tentacles, stomodaeum or mouth structures, shell, etc., were missing, while larval head cells, liver, ganglia and muscle cells were present. Consequently we may conclude that after first cleavage the $A B$ cell has limited developmental capacities and that it is the compact half of the separation experiments. A section of a known AB-half-embryo is shown on plate 1 , figure 5 .

In five cases the AB-half was killed. The CD-halves developed into balloon-like embryos, which were reared for 15 days. In sections of four of these CD-embryos an eye appeared to be present, but tentacles were never observed. All showed shell, operculum and statocyst. Two of them showed mouth structures, one even a well developed radula. In conclusion we may state that it is from the CD blastomere that all adult structures can develop and that $C D$ is the swollen half of the separation experiments. A section of a CD-half-embryo is shown on plate 1 , figure 6.

\section{$B$. The development of $A D$ - and $B C$-halves}

The separation of $\mathrm{AD}$ - and $\mathrm{BC}$-halves was carried out just after the completion of second cleavage, when the blastomeres were still rounded. In order to ascertain the separation of the correct pairs, all eggs, selected for operation, were observed from the beginning of second cleavage.

The development of 2/4-halves (AD and $B C$ ) is better than of 1/2-halves ( $A B$ and CD) separated at first cleavage. Both halves develop in the same way; they never become swollen embryos. From 60 egg masses 295 eggs were operated at second cleavage. In 67 cases both halves originating from the same egg were cultured for $14-16$ days at $25^{\circ} \mathrm{C}$. During this period many adult structures such as eyes, tentacles, shell, stomach, etc., originate.

Forty pairs were studied as whole mounts stained with silver nitrate. The results

TABLE 3

Summary of the structures present in 40 pairs of half-embryos (AD and BC) studied as whole mounts after silver staining

\begin{tabular}{lccc}
\multicolumn{1}{c}{ Organs } & $\begin{array}{c}\text { Present in } \\
\text { both halves }\end{array}$ & $\begin{array}{c}\text { Present in } \\
\text { one half only }\end{array}$ & $\begin{array}{c}\text { Absent in } \\
\text { both halves }\end{array}$ \\
\hline Larval head structures & 40 & - & - \\
Eye & 17 & 18 & 5 \\
Tentacle & 17 & 21 & 2 \\
Shell & 18 & 22 & 19 \\
Operculum & 9 & 12 & 11 \\
Gills & - & 29 & 1 \\
\hline
\end{tabular}


are summarized in table 3 . An example of two 2/4-embryos originated from the same egg, is shown in figure 2.

All 40 pairs of $2 / 4$-embryos showed larval head cells, although these were never organized as in a normal head. One eye in each of these halves was observed in 15 cases and two eyes in one and one eye in the other half in two other cases. Eighteen 2/4-embryos showed an eye in only one partner and in five pairs eyes were absent in both halves.

One tentacle was present in each partner in 12 pairs; one half-embryo with two, the other with one tentacle in three pairs and one half-embryo with two, the other with three tentacles in two pairs. Sixteen half-embryos showed one tentacle, 3 two and 2 three tentacles, whereas in the partners this structure was absent.

A shell was present in both halves in 18 pairs. In 22 cases it was found in one half only. A single operculum in both halves was observed in seven partners; one operculum in one and two opercula in the other half in two cases. In 12 pairs only one half showed this structure, which in two cases was present twice. In 19 cases it was absent in both partners.

Gills were the only structure, which never was observed in both members of a pair of 2/4-embryos. They were absent in 11 pairs and in 29 cases present in one half.

Twenty-seven pairs of 2/4-embryos were studied in sections stained with iron haematoxylin. The results are shown in table 4. Examples are shown on plate 2, figures $7-8$ and $9-10$.

Larval head cells, not normally organized into specific structures, were observed in all half-embryos. One eye was present in both partners of ten pairs; in three one half showed two and one a single eye. In ten pairs an eye was found in one of the two partners; in two pairs one partner showed two eyes, missing in the other and in two cases an eye was absent in both 2/4-embryos.

A single tentacle present in each halfembryo was found in seven pairs, in two cases two tentacles in one half and one in the other, and in one case two tentacles in each 2/4-embryo were observed. In eight
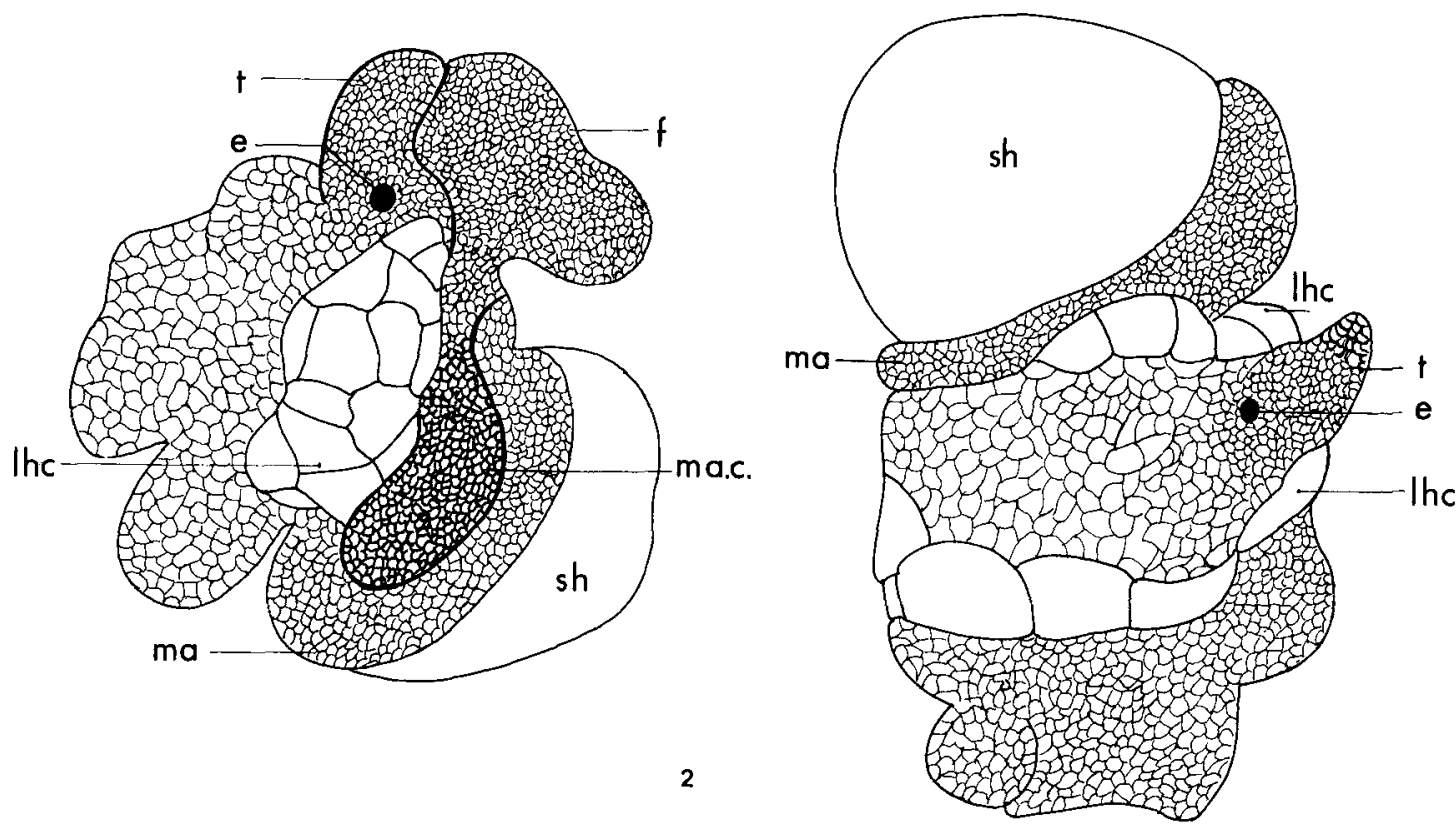

Fig. 2 Silverstained whole mounts of two 2/4-embryos from a single egg. Both have a tentacle (t), an eye (e), a shell ( $\mathrm{sh}$ ) with mantle (ma), mantle cavity (ma.c) [not visible in this view of the right embryo] and larval head cells (lhc). A distinct foot (f) is present only in the left embryo. 
TABLE 4

Summary of structures present in 27 pairs of half-embryos ( $A D$ and $B C$ ) studied in sections

\begin{tabular}{|c|c|c|c|}
\hline Organs & $\begin{array}{l}\text { Present in } \\
\text { both halves }\end{array}$ & $\begin{array}{l}\text { Present in } \\
\text { one half only }\end{array}$ & $\begin{array}{l}\text { Absent in } \\
\text { both halves }\end{array}$ \\
\hline Larval head structures & 27 & - & - \\
\hline Eye & 13 & 12 & 2 \\
\hline Tentacle & 10 & 15 & $\overline{2}$ \\
\hline Shell & 10 & 14 & 3 \\
\hline Operculum & 4 & 15 & 8 \\
\hline Gills & - & 18 & 9 \\
\hline Foot & 4 & 9 & 14 \\
\hline Statocyst & 26 & 1 & - \\
\hline Ganglia & 27 & - & - \\
\hline Muscles & 27 & - & - \\
\hline Foregut & 6 & 11 & 10 \\
\hline Midgut & 27 & - & - \\
\hline Hindgut & 6 & 14 & 7 \\
\hline
\end{tabular}

pairs one half only bore a tentacle and in another seven cases two, whereas the partner had no tentacle. In two pairs no tentacles were present. As regards the relation between eye and tentacle, in 30 cases the eye was found at the base of a tentacle; however in six cases, in which both structures were present in the same half-embryo, they were situated at some distance from each other. In the remaining cases eye and tentacle were not present in the same 2/4-embryo.

With one exception all 2/4-embryos showed at least one statocyst. In 22 halfembryos two statocysts were present and in two half-embryos three.

Several ganglia were present in all halfembryos. On account of the apparently random arrangement of the organs in the $2 / 4$-embryos no attempt to identify individual ganglia has been made.

Shell and operculum were often found together in the same half-embryo. A shell was present in both partners in ten pairs; in one partner in 14 pairs and absent in three pairs. The operculum was found four times in both partners; 14 times in one partner only and in nine pairs it was absent.

On the surface of nearly all half-embryos cells were found with short cilia, often in combination with mucous cells which undoubtedly represent foot epithelium. However, a distinct foot was observed in only four pairs; in nine halfembryos it was present in one of the partners. Gills, often well developed, were always restricted to one partner.

In living embryos a beating heart was observed seven times in both halves of a pair; 11 times in one half and in nine pairs of embryos it was not observed. In all cases this was a larval heart, a thin walled vesicle, which escaped detection in most of the sectioned embryos. In sections a cavity was often observed which looked like the common anlage of pericardium, heart and kidney. As a definite heart or kidney were never identified, it is difficult to decide whether this cavity is the anlage of heart and kidney. Nearly all half-embryos show contractions in later stages. Well-developed muscle fibers, sometimes arranged into muscles, were found in all 2/4-embryos.

The alimentary tract never forms a continuous structure from mouth to anus. The foregut, if present, is already well developed and typical cells, lining the entrance of the stomodaeum in the normal larva, were not observed. As in the control embryos of 16 days the buccal cavity is lined by thick epithelial cells and a well-developed radula with rows of teeth may be present. Foregut structures present in both partners of a pair were observed six times; in one partner 11 times and absent in both partners ten times. An esophagus was rather seldomly (six times) observed in 2/4-embryos and the foregut was never connected with stomach or liver. The stomach was well developed in both partners in three pairs; in 15 pairs it was observed in one partner, while it was missing in nine pairs. Liver tissue was present in all half-embryos. It may be localized as one or more masses inside the embryos, but sometimes it forms a 
part of the surface. When a lumen was present it was often continuous with the lumen of the stomach. Hindgut was observed seven times in both partners of a pair; 13 times in one partner and in seven cases it was absent in both partners. In 13 embryos it connected the midgut with the exterior; in seven it was connected at one end with the midgut, while the other end was closed. In another seven cases there was no connection with the midgut.

\section{DISCUSSION}

In order to give an interpretation of the results we have first to know, which part of the snail originates from $A B, C D, A D$ or $\mathrm{BC}$ in normal development. As molluscs show a determinative cleavage, the origin of the organs can be traced to special cells by cell-lineage studies. The cell-lineage of Bithynia has not yet been completed but we have information on the cell-lineage of related snails such as the prosobranch Crepidula (Conklin, 1894) and the pulmonates Planorbis (Holmes, '00); Physa (Wierzejski, '05); Lymnaea (Verdonk, '65) and Biomphalaria (Camey and Verdonk, 70). The cell-lineage study of Bithynia so far indicates that information from these snails is generally applicable to Bithynia.

The head region of a snail embryo consists of two types of structures: first, larval head structures such as velum, apical plate and head vesicle; second, cephalic plates, from which eyes, tentacles and cerebral ganglia originate. Larval head structures are formed in all four quadrants, so that we may expect them to occur in all $1 / 2$ - and 2/4-embryos. The major part of the left cephalic plate originates from $1 \mathrm{a}^{12}$ and the right one from $1 c^{12}$, while $1 b^{12}$ contributes to both. Conklin (1894) did not use the name "cephalic plates." However, the cell areas from which the cerebral ganglia and eyes in Crepidula originate are identical with the cephalic plates in other snails. He derives these areas from $1 a^{112}$ and from $1 b^{112}$. Clement ('67) in his deletion experiments with Ilyanassa showed that Conklin was incorrect in his derivation of the right eye from $1 b^{112}$. All evidence, available at the moment points the origin of the left eye and tentacle to $1 \mathrm{a}$ and of the right eye and tentacle to $1 \mathrm{c}$. Consequently one may expect these structures to be present in all half-embryos as they all include the A or C quadrant. Nevertheless after separation of $\mathrm{AB}$ and $\mathrm{CD}$ at first cleavage eyes were only observed with certainty in the CD-half-embryos while after separation of blastomeres at second cleavage both $\mathrm{AD}$ and $\mathrm{BC}$ embryos had the capacity to form eyes.

From their origin eyes and tentacles may be expected to occur close together in the half-embryos. In CD-halves an eye frequently occurs but it is seldomly accompanied by a tentacle. The reason may be that these half embryos swell greatly during development, so that the tentacle anlage becomes flattened over the surface. In AD- and BC-halves a single eye is found usually at the base of a tentacle. Sometimes two eyes or two tentacles are observed close together. This can be explained as a doubling or splitting of a single eye anlage. In some cases eye and tentacle remain well separated so that a common origin seems improbable. This may be explained if we assume that in prosobranchs as well as pulmonates $1 \mathrm{~b}$ contributes to the formation of the cephalic plate material. In normal development the cephalic plate cells, which originate from $1 \mathrm{~b}$ are originally separated but later join the anlage of left and right cephalic plate. In BC-halves both $1 \mathrm{~b}$ and 1c form cephalic plates which may not fuse so that both give rise to an eye and/or tentacle.

The shell, according to Conklin (1894) originates from $2 d$. Cather ('67) showed that in Ilyanassa $2 \mathrm{c}$ also contributes to the formation of the shell. Raven ('52) from his study of partially exogastrulated embryos concluded that the formation of the shell gland in Lymnaea is due to an inductive action exerted by the tip of the archenteron on the ectoderm. According to Hess ('56) all 1/2-halves in Bithynia, in which the larval liver was invaginated, show a shell gland. Hess too concluded that there was an induction of the shell gland by the entoderm. Although Hess describes shell gland in supposedly $\mathrm{AB}$ half embryos, we never found shell except in the $\mathrm{CD}$-halves. The AB-halves may show shell gland at younger stages, not studied by us, but if so, shell is never differen- 
tiated by these shell glands, which must then disappear since they were never observed in our $\mathrm{AB}$-halves.

The foot, according to Conklin (1894), originates from both $3 \mathrm{c}$ and $3 \mathrm{~d}$. In $\mathrm{Bi}$ thynia foot was never observed in the $\mathrm{AB}$-halves. In $\mathrm{CD}$-, $\mathrm{AD}$ - and. BC-halves foot epithelium, accompanied by an operculum, was often present, although a wellshaped foot was seldomly observed. Statocysts originate in Ilyanassa in relation with the foot from $3 c$ and $3 d$ (Clement, '62). They were never observed in ABhalves, but in nearly all CD-halves at least one, but often two or three statocysts were present. The same is true for $A D$ - and CD-half-embryos.

Ganglia originate from the ectoderm. As they were found in all half-embryos, their development is rather autonomous.

Heart and kidney are mesodermal structures, whose origin is closely related (cf. von Erlanger, 1892). In the development of molluscs all mesodermal structures originate from the mesentoblast $4 \mathrm{~d}$. In normal development of Bithynia a larval heart is formed, which is an ectodermal vesicle, situated just posterior of the head region. It starts beating at the fifth day of development. In several $\mathrm{CD}$-, $\mathrm{AD}$ - and $\mathrm{BC}$ half-embryos, but never in AB-half-embryos, a beating larval heart was present. The adult heart was never observed with certainty in living embryos. Also in sections it was not possible to distinguish an adult heart or kidney. The origin of mesoderm and mesodermal structures both in normal and half embryos requires tracing them through successive stages of development.

The stomodaeum originates from cells of the second and third quartette of micromeres. After separation of blastomeres at first cleavage Hess ('56) observed a stomodaeum only in one half, which he considered to be the AB-half. However in our experiments stomodaeum or structures originating from it, such as mouth cavity, radula and radular sac were always limited to the CD-halves. After second cleavage foregut structures were found in both $\mathrm{AD}$ - and $\mathrm{BC}$-halves.

In gastropods midgut and hindgut could be traced to the macromeres $4 \mathrm{~A}-4 \mathrm{D}$, while the mesentoblast $4 \mathrm{~d}$ probably contributes to the hindgut. After separation of $\mathrm{AB}$ and $\mathrm{CD}$ at first cleavage in both halves larval liver was found, but the differentiation of the stomach was always limited to the CD-half. As hindgut was found in all half-embryos, apparently the presence of $4 \mathrm{~d}$ is not required for its formation in Bithynia.

We may conclude from the data available from cell-lineage studies that the contribution of $\mathrm{AB}$ to organogenesis is far greater than the organs observed in $\mathrm{AB}$ half embryos. Adult structures such as eyes and tentacles, foregut structures and stomach certainly could be expected but were never observed. Even shell could be expected, when it is induced by the entoderm as liver cells are often situated in side the embryo. Nevertheless shell was never formed in the AB-embryos.

On the other hand both AD- and BChalves, isolated after second cleavage develop organs, which in broad outline also originate from these cells in the intact embryo. Regulation on a broad scale apparently does not occur in Bithynia, as it does in the pulmonate Lymnaea palustris. In isolation experiments Morrill et al. (73) showed that in this snail one blastomere at the 2-cell stage is able to form a complete embryo. This never occurs in Bithynia or Ilyanassa.

Comparing our data with those of Clement ('56) it appears that at first cleavage the developmental capacities of the blastomeres in both prosobranchs Bithynia and Ilynassa are the same. Only from CD do adult organs like eye, tentacle, shell, etc., develop. However after second cleavage the situation is quite different. In Ilyanassa only the D macromere or combinations containing the $\mathrm{D}$ macromere may give rise to embryos with adult structures. In Bithynia these structures form not only from the AD-half but they also arise from the BC-half.

An investigation of ooplasmic segregation was then done to determine if there was some common factor which could explain the fact that both $\mathrm{AD}$ - and $\mathrm{BC}$ halves could give rise to adult structures. Stages from the uncleaved egg to four cells were investigated in detail (Dohmen and Verdonk, to be published). At first cleavage a distinctive cup-shaped cytoplasm, rich in RNA, is present in the polar lobe. This cytoplasm is passed ex- 
clusively to the $C D$ blastomere with the fusion of the lobe. In this way it appears that the $C D$ cell gets developmental capacities not present in the $A B$ cell. At the beginning of second cleavage this special cytoplasm suddenly disappears and is evidently dispersed to the $\mathrm{C}$ and $\mathrm{D}$ blastomeres. This evidence is consistent with the experimental data, which strongly suggests that these blastomeres in Bithynia obtain the same developmental capacities because of an equivalent distribution of this unique cytoplasm.

In Ilyanassa such a special cytoplasm is not visible in the polar lobe (PucciMinafra et al., '69; Geuskens and de Jonge d'Ardoye, '71). Nevertheless the presence of morphogenetic factors in the polar lobe is well established by the experimental work of Clement (71). In Ilyanassa the morphogenetic factors are apparently shunted with the polar lobe exclusively to the CD blastomere and at second cleavage to the $\mathrm{D}$ blastomere. Consequently only the $\mathrm{D}$ blastomere or combinations with the D blastomere develop "lobe dependent" structures, such as eyes, tentacles, external shell, etc. The difference between Bithynia and Ilyanassa appears to be related to the different stages at which the morphogenetic factors, included in the polar lobe, are released. In Bithynia this occurs just at the end of the twocelled stage, when the special cytoplasm breaks down and its fine structural elements are released. In this way the morphogenetic factors are separated to $\mathrm{C}$ and $\mathrm{D}$ at second cleavage.

In Ilyanassa all ABC $+1 \mathrm{~d}$ and most of $\mathrm{ABC}+1 \mathrm{~d}+2 \mathrm{~d}$ larvae develop similarly to lobeless embryos. After removal of 3D all adult organs except the heart and intestine are present and after $4 \mathrm{~d}$ is included a structurally complete embryo is formed (Clement, '62). The most obvious explanation is that in Ilyanassa the cytoplasmic determinants, originally present in the polar lobe, are gradually distributed to the D quadrant micromeres. Apparently the morphogenetic factors of the polar lobe in Ilyanassa are restricted to the $\mathrm{D}$ quadrant for a much longer time than in Bithynia.

The polar lobe of Bithynia, although very small, with a volume less than $1 \%$ of the total egg volume, has nevertheless the same morphogenetic influence as the much larger lobe of Ilyanassa. Since this lobe contains an unusual cytoplasm, not previously described in the polar lobe of other molluscs, it appears particularly well suited for further investigations.

\section{ACKNOWLEDGMENTS}

The authors wish to thank Professor Dr. Chr. P. Raven for his encouragement during the course of this work and for critically reading the manuscript. The second author wishes to express his appreciation to Professor Raven for the hospitality of his laboratory. We sincerely appreciate the excellent technical assistance of Mr. Gideon Zwaan.

\section{LITERATURE CITED}

Atkinson, J. W. 1971 Organogenesis in normal and lobeless embryos of the marine prosobranch gastropod Ilyanassa obsoleta. J. Morph., 133: $339-352$.

Camey, T., and N. H. Verdonk 1970 The early development of the snail Biomphalaria glabrata (Say) and the origin of the head organs. Neth J. Zool., 20 (1): 93-121.

Cather, J. N. 1967 Cellular interactions in the development of the shell gland of the gastropod, Ilyanassa. J. Exp. Zool., 166: 205-223.

- 1971 Cellular interactions in the regulation of development in annelids and molluscs. In: Advances in Morphogenesis. Vol. 9. M. Abercrombie, J. Brachet and Th. J. King, eds. Academic Press, New York, pp. 67-125.

Clement, A. C. 1952 Experimental studies on germinal localization in Ilyanassa. I. The role of the polar lobe in determination of the cleavage pattern and its influence in later develop. ment. J. Exp. Zool., 121: 593-626.

- 1956 Experimental studies on germinal localization in Ilyanassa. II. The development of isolated blastomeres. J. Exp. Zool., 132: $427-446$

1962 Development of Ilyanassa follow. ing removal of the $D$ macromere at successive cleavage stages. J. Exp. Zool., 149: 193-216.

_ 1967 The embryonic value of the micromeres in Ilyanassa obsolett! as determined by deletion experiments. I. The first quartet cells J. Exp. Zool., 166: 77-88.

1971 Ilyanassa. In: Experimental Embryology of Marine and Fresh-water Invertebrates. G. Reverberi, ed. North Holland Publishing Company, Amsterdam, pp. 188-214.

Conklin, E. G. 1894 The embryology of Crepidulit. J. Morph., 13: 1-226.

Crampton, H. E. 1896 Experimental studies on gastropod development. Arch. Entw. mech., 3: 1-19.

Erlanger, R. von 1892 Beiträge zur Entwicklungsgeschichte der Gastropoden. Mitth. Zool Stat. Neapel, 10: 376-407.

Geuskens, M., and V. de Jonge d'Ardoye 1971 Metabolic patterns in Ilyanassa polar lobes. Exp. Cell Res., 67: 61-72. 
Hess, O. 1956 Die Entwicklung von Halbkeimen bei dem Sûsswasser-Prosobranchier Bithynia tentaculata L. Roux' Arch. Entw. mech., 148: 336-361.

Holmes, S. J. 1900 The early development of Planorbis. J. Morph., 16: 369-458.

Morrill, J. B., C. A. Blair and W. J. Larsen 1973 Regulative development in the pulmonate gas. tropod Lymnaea palastris, as determined by blastomere deletion experiments. J. Exp. Zool., 183: 47-56

Pucci-Minafra, I., S. Minafra and J. R. Collier 1969 Distribution of ribosomes in the egg of Ilyanassa obsoleta. Exp. Cell Res., 57: 167-178.

Rattenbury, J. C., and W. E. Berg 1954 Embryonic segregation during early development of Mytilus edulis. J. Morph., 95 : 393-414.
Raven, Chr. P. 1952 Morphogenesis in Limnaea stagnalis and its disturbance by lithium. J. Exp. Zool, 121: 1-77.

Verdonk, N. H, 1965 Morphogenesis of the head region in Limnaea stagnalis. Thesis Utrecht. 1968 The relation of the blastomeres to the polar lobe in Dentalium. J. Embryol. exp. Morph., 20: 101-105.

Wierzejski, A. 1905 Embryologie von Physa fontinalis L. Z. wiss. Zool., 83: 502-706.

Wilson, E. B. $1904 \mathrm{a}$ Experimental studies on germinal localization. I. The germ-regions in the egg of Dentalium. J. Exp. Zool., 1: 1-72.

$1904 \mathrm{~b}$ Experimental studies on germinal localization. II. Experiments on the cleavage mosaic in Patella and Dentalium. J. Exp. Zool., 1: $197-268$ 


\section{PLATE 1}

\section{EXPLANATION OF FIGURES}

3-4 Sections through the two 1/2-embryos from a single egg. One halfembryo (fig. 3) shows a mass of muscle cells (m), larval liver (1) and a ganglion (g). The other half-embryo (fig. 4) shows two statocysts (sc), two ganglia (g), larval liver (1), stomodaeum entrance cells ( $s d$ ) and a radula ( $r$ ). A section of the turret-like shell of this embryo is situated to the right. The empty, swollen part (sv) of this embryo collapsed at fixation. Staining: iron haematoxylin and eosin. About $\times 225$.

5 Section through a known AB-half-embryo, showing well developed ganglia (g) and muscle cells (m). Only the edge of the larval liver (l) is seen in this particular section. Staining: iron haematoxylin and eosin. About $\times 225$.

6 Section through a known CD-half-embryo, showing an eye (e), statocyst (sc), oesophagus (oe) and mantle edge (me). A small part of the shell (sh) can be seen here. The empty, swollen part (sv) collapsed at fixation. Staining: iron haematoxylin and eosin. About $\times 225$. 

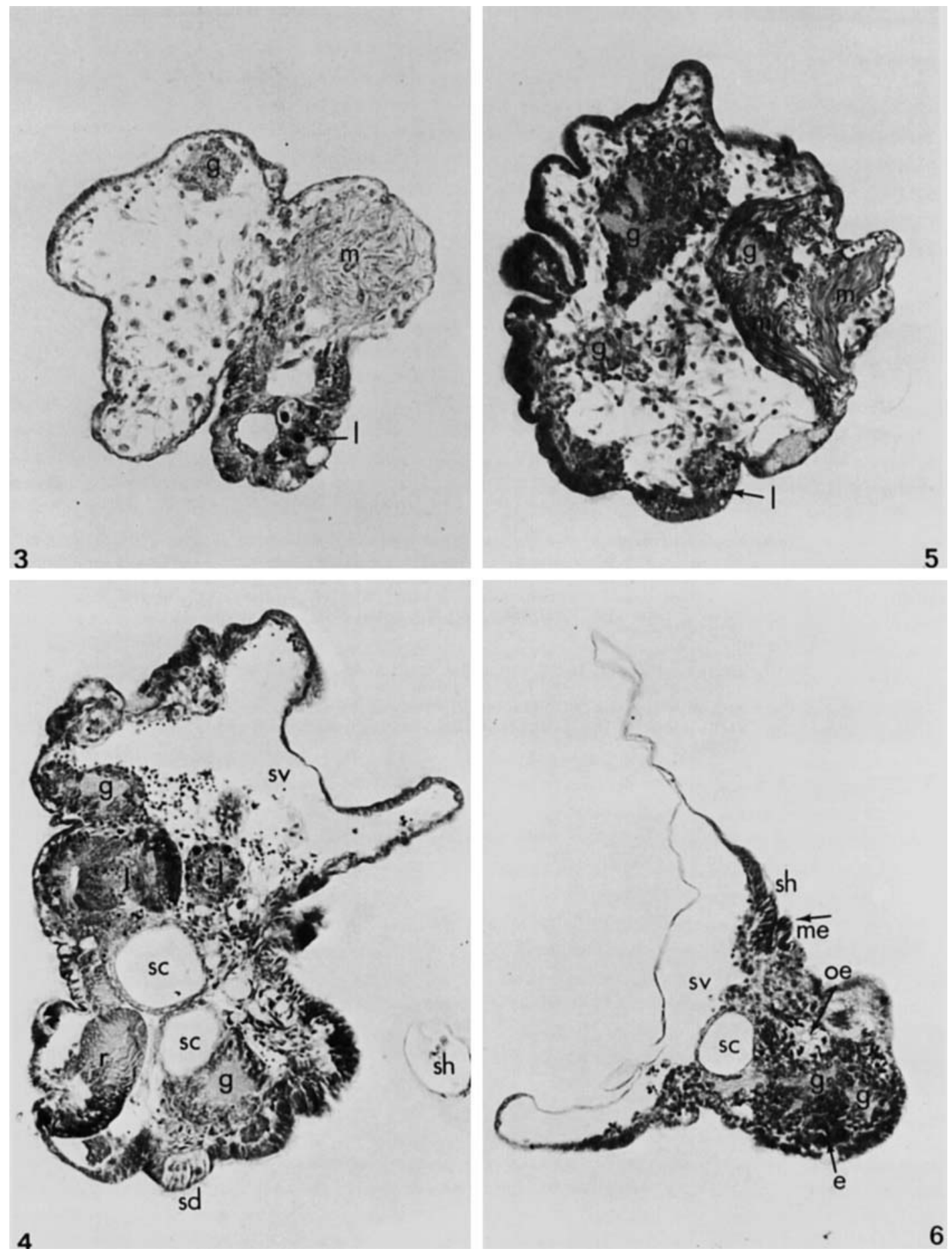
PLATE 2

EXPLANATION OF FIGURES

7-8 Sections through two $2 / 4$ embryos from a single egg. Figure 7 shows an eye (e) at the base of a tentacle ( $t$ ), stomach (sm), larval liver (l), ganglia $(\mathrm{g}$ ) and muscle cells $(\mathrm{m})$. Figure 8 shows a radula $(\mathrm{r})$, shell (sh), operculum (o), larval liver (l), ganglia (g) and muscle cells (m). Staining: iron haematoxylin and eosin. About $\times 225$.

9-10 Sections through two 2/4-embryos from a single egg. Both embryos show an eye (e) at the base of a tentacle ( $t$ ), shell (sh), ganglia (g) and muscle cells (m). The larval liver can be seen here only in the right embryo (fig, 10). Staining: iron haematoxylin and eosin. About $\times 225$ 

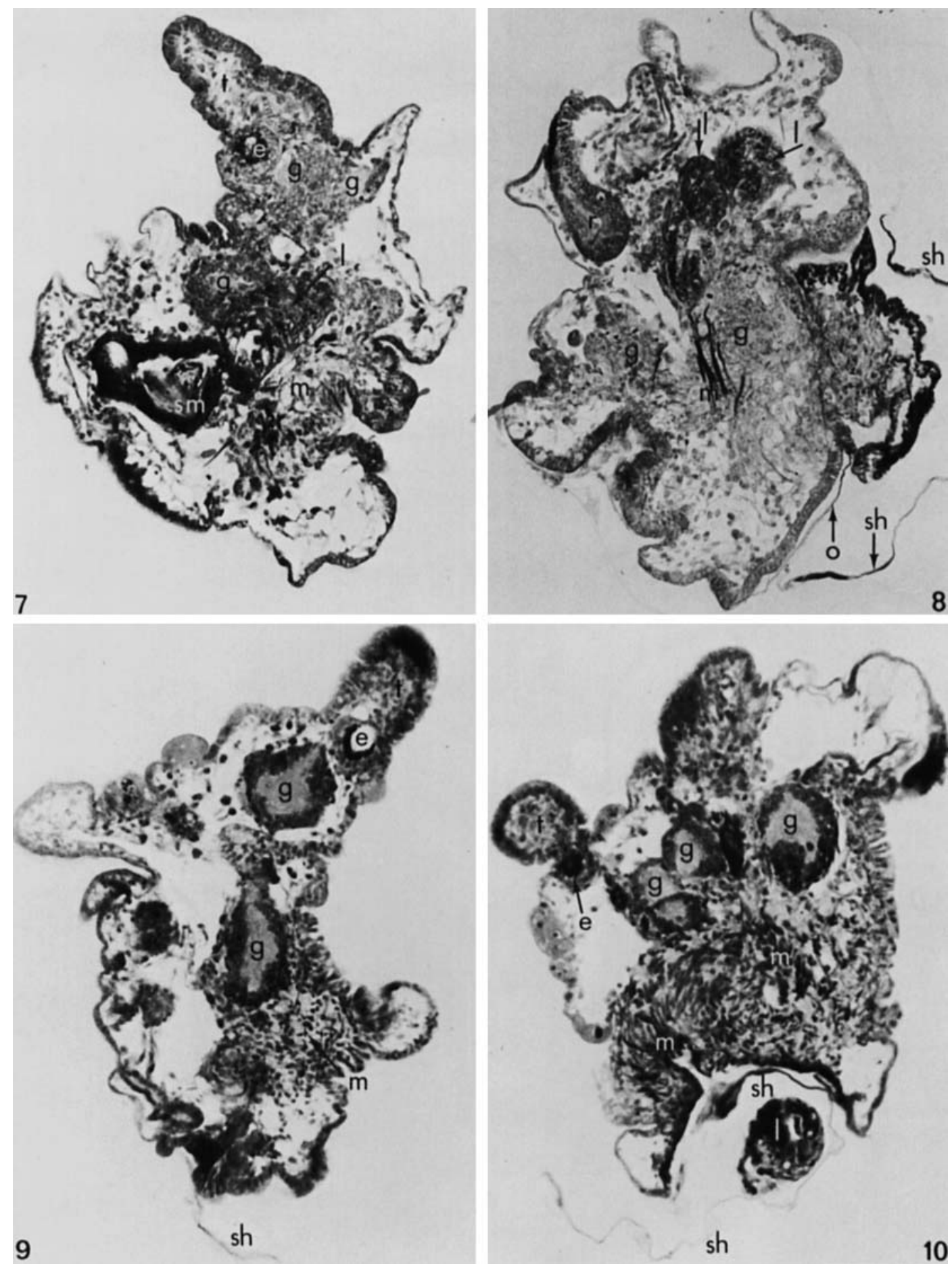